\title{
Terapia ocupacional e pessoas em situação de rua: criando oportunidades e tensionando fronteiras
}

\author{
Marta Carvalho de Almeida, Denise Dias Barros, \\ Débora Galvani, Tiy de Albuquerque Maranháo Reis
}

\begin{abstract}
Resumo: O trabalho expõe e discute ações de Terapia Ocupacional desenvolvidas junto a adultos em situação de rua, na cidade de São Paulo, SP, no período de 2003 a 2006, como parte das atividades do Projeto METUIA - Núcleo USP-UFSCar em parceria com a Associação Minha Rua Minha Casa. Enfoca, especificamente, o trabalho com grupos de usuários dessa organização e descreve estratégias e recursos adotados para produzir uma conexão significativa entre as ações da Terapia Ocupacional Social e as necessidades dos participantes. A reflexão sobre essa experiência, que buscou promover oportunidades diversificadas para o exercício e a ampliação das trocas sociais, leva a considerar que as ações do Terapeuta Ocupacional junto a esse segmento da população devem interagir criticamente com diferentes fronteiras, inclusive as metodológicas. Notou-se que a flexibilidade dos componentes que estruturam a intervenção é essencial para permitir a permanente incorporação das necessidades relacionadas ao processo de constituição da pessoa em situação de rua como sujeito de direitos. A flexibilidade atua, também, em oposição à instalação de expectativas de progressos lineares.
\end{abstract}

Palavras-chave: Terapia Ocupacional, Serviços de Assistência Social, Participação Social.

\section{Occupational therapy and the homeless: creating opportunities and tightening borders}

\begin{abstract}
This study presents and discusses occupational therapy actions developed with the adulthomeless population in Sao Paulo, between 2003 and 2006, as a part of the "METUIA Project - USP-UFSCar Branch", in partnership with the "MinhaRua,Minha Casa"Association. It focuses on the group work done with this organization's users, during the confection of imitation jewelry (bijou), and describes the strategies and resources used to produce a significant connection between 'Social Occupational Therapy' actions and the users' needs. Reflection on this experience, which sought to promote diversified opportunities of exercising and expanding social exchanges, leads us to believe that the occupational therapist's actions with this segment of the population must be confronted on many borders, including methodological ones. The flexibility of the components that structure the intervention was seen as essential to allow the permanent incorporation of requirements needed for the constitution process of the homeless as a subject of rights. Such flexibility also works against the idea of expecting linear forms of progress.
\end{abstract}

Keywords: Occupational Therapy, Social Services, Social Participation.

\section{Introdução}

Este trabalho reflete nosso interesse em compartilhar e discutir a intervenção de Terapia Ocupacional que ocorreu entre os anos de 2003 e 2006, na cidade de São Paulo-SP, junto a pessoas em situação de rua, como parte das atividades do
Projeto METUIA ${ }^{1}$ - Núcleo USP-UFSCAR. Tal intervenção aconteceu na Associação Minha Rua Minha Casa (AMRMC), que é uma Organização Não Governamental (ONG) conveniada com a prefeitura do Município de São Paulo e está situada 
sob o viaduto do Glicério, no centro da cidade. Considerando-se as categorias definidas no PLAS ${ }^{2}$ de 2006, a AMRMC atuava naquele período como Núcleo de Serviço e Convivência, sendo importante referência assistencial para as pessoas em situação de rua. Diariamente, atendia aproximadamente 200 pessoas.

As orientações teórico-práticas adotadas para o planejamento, a execução e a avaliação do trabalho que se realizou e que aqui é descrito situam-se no campo da Terapia Ocupacional Social que, ao atuar com contingentes da população que vivem diferentes processos de vulnerabilidade das redes relacionais e dissolução de vínculos sociais, propóe que as noçôes de cidadania e de produçáo de identidades sejam guias da interpretação da demanda e da formulação de projetos de intervenção (BARROS, 2004).

\section{Viver na e da rua: algumas faces do problema}

No Brasil, nas três últimas décadas, foram usadas varias expressóes para designar pessoas que vivem nas ruas das grandes e médias cidades. Como mostrou Rosa (2005), "mendigos", "vagabundos", "trecheiros", "sofredores de rua" e "população de rua", entre outras, expressaram diferentes representaçóes presentes na sociedade brasileira sobre essas pessoas, bem como a conjuntura social, econômica e política dos períodos históricos em que foram empregadas. Considera-se que uma expressão adequada para designar as pessoas que utilizam a rua como espaço de moradia e sustento ainda constitui um problema teórico não resolvido, tendo em vista que mesmo as expressóes mais adotadas comportam imprecisóes, deficiências e, muitas vezes, preconceitos, como discutem Kubota, Pires e Neves (2008).

Aqui, tal como outros autores que fazem uso crítico de diferentes expressōes em vigor, adotaremos população em situação de rua para designar o grupo de pessoas que, vivendo nos logradouros públicos, como ruas, praças e viadutos, ou alternadamente em albergues, sobrevive em situação de extrema pobreza e insegurança, e experimenta precariedades e privaçóes diversas no plano material, afetivo, social, político e ético. Frequentemente, essas pessoas são cercadas por atitudes sociais de desprezo, negação e violenta apartação social. A expressão população em situação de rua também tem sido utilizada no campo das políticas públicas e integra a Política Nacional para a População em Situação de Rua (BRASIL, 2009), que acentua que este é um grupo populacional heterogêneo, que tem em comum a pobreza extrema, os vínculos familiares interrompidos ou fragilizados e a inexistência de moradia convencional regular. Com base nas proposições de Castel (1994, 1998), que analisa as diferentes formas de integração à sociedade por meio dos eixos do trabalho e da sociabilidade sociofamiliar, pode-se dizer que a população em situação de rua é um segmento social que transita por zonas de vulnerabilidade e de desfiliaçáo social.

Sob a perspectiva da integraçáo ao mundo do trabalho e do acesso aos mecanismos de proteçáo social associados a este, o morador de rua contemporâneo transformou-se em sujeito emblemático da categoria exclusão social (TOSTA, 2000). A mundialização da economia e a reestruturação produtiva que se instalou nos países latino-americanos a partir da década de 1980 afetaram profundamente as condiçôes de reprodução do trabalho e, assim, a lógica econômica que propicia o incremento da produção de forma paralela a uma brutal redução do emprego do trabalho humano tem empurrado populaçôes empobrecidas no rumo da exclusão (BURSZTYN, 2000). Para esse segmento da população, o processo de exclusão no e pelo mundo do trabalho repercute profundamente nos demais domínios da prática social (NASSER, 2001).

Embora não se possa responsabilizar apenas os processos econômicos pela permanência temporária ou duradoura de pessoas nas ruas, na medida em que há um conjunto variado de fatores que se associam e condicionam esse fenômeno social, a desvinculação do mercado de trabalho formal e a ruptura dos vínculos familiares são componentes quase sempre presentes nas histórias de vida dessas pessoas. Dentre os entrevistados, em estudo do Ministério do Desenvolvimento Social e Combate à Fome (MDS), 71,3\% apontaram ao menos um destes motivos como razão para estarem na rua: problemas relacionados ao uso de álcool ou drogas, desemprego e desavenças familiares (BRASIL, 2008). Na medida em que se deparam com programas sociais marcados pela institucionalização de práticas associadas ao descarte social (VARANDA; ADORNO, 2004), não encontram, nestes, oportunidades de reestruturaçáo de suas vidas.

Contudo, alguns estudos brasileiros concordam que, mesmo sendo a vida na rua o ponto extremo de trajetórias de desvinculaçáo com o trabalho, a família, a moradia e o mercado, processam-se nessa condição movimentos de reconstrução de laços, de formação de grupos de pertencimento, bem como estratégias grupais de sobrevivência que se apoiam em uma rede de organizaçóes que com elas colaboram direta ou indiretamente (ALVAREZ, 1999; GALVANI, 2008; GALVANI; BARROS, 2010; JUNCÁ, 2004; 
MATTOS, 2006; ROSA, 2005). Nas trajetórias de vida que compóem esses estudos, aparecem não somente as relaçóes perdidas, mas a constituiçáo de novos vínculos e elos de solidariedade, que se dão a partir da vida na rua. Ainda que, por vezes, sejam descontínuas, frágeis e contraditórias, permitindo acesso parcial e precário à geração e à distribuição de bens e valores sociais, essas relações configuram um campo no qual frequentemente se viabiliza a sobrevivência física, afetiva e social dessas pessoas.

\section{Criando encontros e} oportunidades: passos
de um caminho

Os aspectos mencionados até aqui para caracterizar o problema das populaçôes em situação de rua foram referências importantes para que se definissem os aspectos essenciais do conjunto de açôes realizadas durante a parceria METUIA-AMRMC, tais como diretrizes, estratégias, recursos e processos. Apostar na possibilidade de atuar em oposiçáo aos fatores que empurram pessoas em situação de rua no caminho da diluição da sociabilidade e de seus projetos de vida foi fundamental. E apostar nas possibilidades de estimular e apoiar diferentes formas de resistência individual e coletiva à desumanização mostrou-se essencial, também.

Entre as diversas açốes desenvolvidas no contexto dessa parceria, neste relato damos destaque a uma delas, que se desenvolveu predominantemente por meio da modalidade de atenção grupal, orientada pela confecção artesanal de bijuterias.

O trabalho aconteceu por meio da proposição de dois diferentes grupos, ambos com propostas específicas, mas complementares. Ambos os grupos tinham por objetivo criar um território no qual fosse possível que seus integrantes inventassem linhas de fuga da pobreza relacional, seja esta decorrente do isolamento, da falta de interlocuçáo com o entorno social, ou das relaçôes hierarquizadas, de dominação e controle, que assujeitam e invalidam saberes, desejos, necessidades e histórias, tão predominantes nas relaçóes assistenciais, segundo relatos dos assistidos.

Num plano, o objetivo era criar oportunidades para o participante experimentar, aprender, ensinar, criar e, assim, reconhecer-se sujeito, com história, desejos, direitos, potências e fragilidades. Noutro, era oferecer oportunidades para a criação ou o fortalecimento de redes relacionais, para a invençáo de espaços de pertencimento, para a construção de pontes de acesso a direitos, para a elaboração e a mobilização de processos orientados para a emancipação pessoal. Esses planos atravessaram permanentemente o trabalho desenvolvido nos dois grupos.

\section{Aproximações: o Grupo de Experimentação}

Um dos grupos, que aqui denominaremos de Grupo de Experimentação, ocorria no pátio central da AMRMC semanalmente, no horário em que havia maior circulação de pessoas: das 14:00 às 17:00 horas. O pátio central é o primeiro espaço que o usuário encontra ao chegar à AMRMC. É amplo, coberto apenas pela estrutura do viaduto e cercado por algumas salas laterais que são construídas em alvenaria. Seu mobiliário é composto basicamente por mesas, cadeiras e bancos, nos quais os usuários tomam lugar para se alimentar, conversar, ler ou apenas permanecer. Nos períodos da tarde, nos quais aconteciam os grupos, a AMRMC se mantinha aberta para qualquer interessado, oferecendo serviços diversos: guarda de volumes, utilização de tanques e varais para limpeza e secagem de roupas, banho quente, lanche da tarde e algumas atividades socioeducativas. Circulava no espaço uma população bastante heterogênea no que diz respeito à faixa etária, à sociabilidade e às demandas verbalizadas. A maior parte dessa população vinha mesmo para o lanche da tarde, servido sempre às 15:00 horas pelos usuários da AMRMC denominados "associados". Com vínculo diferenciado com a organização, os associados tinham compromissos e benefícios exclusivos, que incluíam a permanência na AMRMC desde o período da manhã e a preparação do lanche, sua oferta, e a limpeza do ambiente e utensílios utilizados.

Com base no perfil dos frequentadores da tarde, o Grupo de Experimentaçâo foi pensado para favorecer as experiências iniciais de contato e o acolhimento das diferentes demandas. Não apenas o contato da populaçáo em situação de rua com o outro - seja o profissional da equipe, seja outro usuário da AMRMC -, mas também o contato com a possibilidade de criar, produzir, inventar, dentro dos limites da atividade proposta: a confecção artesanal de bijuterias. $\mathrm{O}$ contexto deveria, portanto, ser bastante receptivo e flexível, e permitir, primordialmente, o início da construçáo de aproximaçóes, de diálogos, de processos de reconhecimento mútuo entre profissionais e usuários, fundamentados na afirmaçáo dos direitos da população em situação de rua e na potência daqueles que a compóem. E assim se deu. Havia profissionais ${ }^{3}$ em número adequado para estabelecer interaçôes duais com um número grande de usuários, materiais e ferramentas amplamente disponíveis, e nenhum requisito moldando o ingresso ou a permanência no ambiente em que se dava a reunião do grupo. 
Grande parte dos que buscavam a AMRMC à tarde era usuária esporádica ou estava essencialmente interessada em algum serviço oferecido pela organização, não tendo ainda laços mais estáveis com a equipe ou outros usuários. Romper o silêncio, o isolamento, a apatia e o distanciamento socioafetivo característicos daqueles que se aproximavam da atividade grupal, ainda um tanto desconfiados e céticos, não era tarefa simples. Com o tempo, contudo, constatou-se a importância inequívoca da manutenção desse formato de atividade como parte do projeto de trabalho. Com a tônica na experimentação, o espaço se mostrou fundamental para promover vivências pouco estruturadas e com baixo grau de exigências, que se mostraram relevantes como dispositivo de acolhimento, principalmente para aqueles com maiores dificuldades de interação. Ali no grupo, a falta de conhecimento, de habilidades e de propósitos não era problema. A todo encontro, promovia-se uma ambiência de "iniciação".

Embora sua localização tenha sido alterada algumas vezes, qualquer usuário da AMRMC que entrasse no pátio poderia ver, mesmo de longe, as atividades e os participantes do grupo, e podia se aproximar sem ser convidado, tendo em vista a inexistência de barreiras físicas e de regras de ingresso. Desse modo, o número de participantes era sempre variável, entre 10 e 25 pessoas. O tempo de permanência, bem como o horário de entrada e saída, era livre, o que definia a existência de períodos com maior e menor número de participantes. Algumas vezes, até mesmo as crianças participavam com seus pais, impondo dinâmicas específicas.

Foram produzidas muitas bijuterias nessas ocasiōes. A possibilidade de concluir o ciclo de produção numa mesma tarde foi um aspecto importante do trabalho. Quase todos os participantes levavam suas peças concluídas ao sair e se mostravam satisfeitos com isso. Essas peças - brincos, colares, pulseiras carregavam significados variados. Frequentemente, eram destinadas a presentear alguém ou a adornar o próprio corpo, o que nos parecia bastante interessante, visto se tratarem de objetos que permitiam conexóes com afetos importantes, ligados à autoestima ou à criação/preservação de laços afetivos.

Embora a participação de parte dos usuários tenha sido irregular, no que diz respeito à frequência, muitas interaçôes foram produzidas nesses momentos grupais. Algumas dessas desdobraram-se em novas redes relacionais que, com o tempo, ganharam complexidade e passaram a abranger outros espaços de convivência, dentro e fora da AMRMC.

\section{5 "Ideias novas": o fazer artesanal}

A todos os participantes do Grupo de Experimentação, era oferecida a possibilidade de participar de outro encontro, que ocorria semanalmente em outro dia, horário e espaço da AMRMC, quando se colocava em circulação diferentes tipos de linguagens técnicas e ideias relacionadas à confecção de bijuterias. Alguns aceitavam prontamente o convite. Outros, só se tornariam participantes após um grande período de participação no Grupo de Experimentação.

Esse segundo encontro semanal também acontecia à tarde e era aberto à participação voluntária de quem nele encontrasse um sentido pessoal. Mais uma vez, a inclusão no grupo foi concebida como direito de todos - prescindindo de capacidades, habilidades, regularidade da frequência ou qualquer outro pré-requisito. Porém, o espaço em que os encontros aconteciam era mais delimitado, consistindo em uma grande sala fechada, distinta do grande pátio da AMRMC, e náo visível a todos. O local tinha menos barulho e era mais propício a rodas de conversa. Também era mais adaptado à realização de atividades artesanais, pois o mobiliário e sua disposição eram apropriados. Havia estantes e uma grande mesa central. Uma vez que também era proposta ao grupo a aquisição processual de novas habilidades relacionadas especificamente à confecção artesanal de bijuterias, o acondicionamento, a organizaçáo e a manutençáo de materiais e equipamentos de modo permanente era um fator importante ${ }^{4}$.

Embora o ingresso nessa atividade grupal também fosse aberto a todos, mais frequentemente os participantes eram pessoas cujo contato já se havia iniciado no Grupo de Experimentação em momento anterior, o que nos levava a identificar a complementariedade das atividades grupais no que diz respeito à participação dos componentes. Sem um acolhimento inicial bastante cuidadoso, promovido no Grupo de Experimentação, talvez náo tivesse havido a participaçáo de um número significativo de pessoas nesse outro momento grupal.

Sendo um grupo aberto, seus componentes variavam a cada dia. Porém, ao longo do tempo, o grupo passou a contar com um núcleo de participantes assíduos, cujas demandas definiram as diretrizes e os modos de continuidade do trabalho. O estímulo ao protagonismo dos participantes mostrava resultados importantes, uma vez que o que se viu foi a emergência de projetos individuais e coletivos que envolviam a confecção de bijuterias. 
Os participantes irregulares ou esporádicos também eram acolhidos e frequentemente se integravam ao grupo, possivelmente por causa da solidariedade e da flexibilidade que vigoravam no ambiente. Aliás, não era incomum a presença de pessoas que apresentavam dificuldades de se inserir em outras atividades e/ ou grupos da AMRMC. Estas eram incluídas no grupo e se tornavam observadores ou participantes, com suas contribuiçóes e dificuldades peculiares. De fato, o grupo se instituiu como um importante espaço de acolhimento e respeito às diferenças. Dos encontros, participavam jovens, adultos, idosos, homens e mulheres, com diferentes interesses, habilidades, objetivos, projetos e necessidades. Todos eram reconhecidos e seus projetos de fazer artesanal eram legitimados e implementados, na medida do possível. Os conflitos que dessa heterogeneidade de interesses decorriam eram trazidos à discussão coletiva e a convivência em grupo gerava negociação e pactuação em movimento permanente, tal como, de fato, se dava com todos os aspectos da vida grupal.

Alguns participantes chegavam ao grupo ainda com pouca habilidade para a realização da atividade proposta. Outros queriam aprender a confeccionar peças mais complexas (conhecidas por meio de revistas ou em lojas comerciais) ou experimentar novos efeitos estéticos decorrentes da utilização de materiais específicos. Outros, ainda, já com conhecimentos prévios e habilidades bem desenvolvidas, requeriam condiçóes adequadas para colocar em andamento seus saberes e fazeres. Parte dos integrantes mostrou conhecimentos prévios e/ou interesse no trabalho de tecelagem. Estes também foram se agregando ao grupo e era comum que essas pessoas realizassem tanto a tecelagem quanto a confecção de bijuterias.

As habilidades eram reconhecidas e valorizadas. E cabe dizer que a ampliação dessas habilidades - seja para os iniciantes, seja para os que estavam em estágios mais avançados - sempre se deu por meio de processos informais de aprendizagem, nos quais as estratégias empregadas podiam ser variadas e se estabelecer de acordo com o ritmo do aprendiz.

Com o passar do tempo, alguns participantes passaram a experimentar de modo individual as possibilidades de adquirir renda com os produtos confeccionados. Inicialmente, os levavam para os albergues e outros espaços externos à AMRMC. Ao receberem elogios de alguns profissionais da assistência e também de colegas, passaram a perceber a possibilidade de vendê-los. Assim, as demandas do grupo relacionadas à obtenção de renda por meio dos produtos foram aumentando progressivamente e parte do trabalho se voltou para a relação produtosmercado. Ao mesmo tempo, o ambiente permaneceu aberto e acolhedor para todos, inclusive para aqueles que queriam apenas desfrutar da convivência grupal. Alguns chegavam e faziam uma pequena peça. Para aprender, para presentear alguém ou para si mesmos. Outros, só conversavam. Outros, ainda, só apareciam na hora do lanche ou para "visita". O ambiente era quase sempre alegre, com muitas conversas.

Com o crescente interesse na obtenção de renda com as bijuterias produzidas, parte dos integrantes passou a se empenhar nessa direçáo, percorrendo novos caminhos e territórios. Explorar e conhecer espaços de comercialização - sejam aqueles de venda de materiais essenciais para a confecção dos produtos, sejam os de comercialização de bijuterias confeccionadas artesanalmente - foram definidos como uma nova açáo do grupo, que também começou a utilizar outros períodos para trabalhar. O grupo se autodenominou, então, "Ideias Novas".

Empreender conexóes com universos externos à AMRMC e ao mundo assistencial que caracteriza a rede social desses participantes, e a consequente extrapolação dos circuitos rotineiros e bem conhecidos, foi um processo rico e intenso. Parece ter gerado experiências significativas para os participantes. No início, foram organizadas excursóes coletivas para se adentrarem novos espaços de trocas sociais, tais como lojas, ateliês, feiras e eventos comerciais. Não era fácil alcançar a presença de todos os participantes e, tanto nos momentos de planejamento como nas diferentes situações em si, evidenciaram-se as restriçôes do acesso aos espaços urbanos, tanto aquelas que se podem caracterizar como típicas da interdição social quanto as que decorriam da autoexclusão dos próprios participantes. Alguns deles, com mais dificuldades, não compareciam no horário combinado para a saída, embora tivessem participado ativamente da organização dessa atividade. Outros se recusavam explicitamente a sair do território conhecido, imobilizados pelo temor da rejeiçáo. Alguns, ao contrário, se preparavam pormenorizadamente para transpor o muro institucional e relacional. Colocavam suas melhores roupas, barbeavam-se, perfumavam-se, como se preparando para uma festa. Evidenciavam-se, nessas situaçôes, as consequências de múltiplas rupturas relacionais e simbólicas com o tecido social mais amplo. Algumas dessas situaçóes propiciaram longas discussóes grupais, nas quais se refletiu sobre as barreiras sociais, seja pela ótica da produçáo social dos mecanismos de apartaçáo e dos obstáculos socialmente criados à integração de alguns segmentos sociais - entre estes, as pessoas em situação de rua - seja pela abordagem da vivência e sofrimento individual de algum integrante. 
Foi interessante notar que as ocasióes de "encontro" com universos externos e distintos foram se multiplicando e, também, sendo ressignificadas no contexto do trabalho. Passaram a ser entendidas simplesmente como parte do processo de trabalho, sem a qual não se chegaria aos objetivos propostos. Não sendo vistas como privilégio nem castigo, tais ocasiōes de "encontros" perderam a centralidade enquanto experiência. Tornaram-se muito frequentes e necessárias as participaçóes de apenas alguns integrantes do grupo, por exemplo, em feiras e eventos nos quais se vendiam as peças confeccionadas pelo conjunto do grupo. Eram espaços de trocas que requeriam o contato direto com o público consumidor e o manejo de dinheiro. Essas participaçôes passaram a ser discutidas e decididas coletivamente, orientadas apenas pelo objetivo mais imediato e com base na divisão de tarefas no grupo, sem gerar grandes conflitos. Algumas vezes, os pequenos grupos de vendedores se formavam de modo a promover apoio mútuo, com base nas afinidades entre estes e nas habilidades próprias de cada um. Um rodízio não muito rígido permitia que todos tivessem essa experiência de tempos em tempos.

É importante dizer que em todas as ocasióes de venda eram disponibilizadas peças de todos os participantes do grupo, em número idêntico. O grupo pactuou que o valor das peças vendidas seria destinado ao artesão que as confeccionou, depois de descontado o valor do custo envolvido na elaboraçáo. O conjunto das parcelas descontadas de cada peça formava o caixa para a compra de novos materiais. Esse funcionamento implicava que, após a confecção de cada peça, fossem discutidos e anotados, discriminadamente, o preço de custo da peça (considerando-se apenas o valor do material) e seu preço de venda. Todos os integrantes participavam desse processo e tinham acesso às anotaçóes. Cada peça tinha um código, por meio do qual era possível saber rapidamente quem a tinha confeccionado.

Também foi implementada uma equipe que cuidava de buscar a colocação das peças em lojas de artesanato, em sistema de consignação. Com diferentes estratégias de relação com o mercado consumidor e com uma razoável complexidade instalada no processo de trabalho, embora se buscasse o respeito às singularidades dos participantes, o grupo precisou responder cada vez mais de modo coletivo às demandas colocadas. Isso requereu, diversas vezes, a explicitaçáo e o manejo de conflitos importantes relacionados às contribuiçôes individuais para a produção coletiva, bem como daqueles relacionados aos ganhos da produção. Muitos aspectos do trabalho eram discutidos durante a confecção das peças, uma vez que era quase impossível que se estabelecessem momentos com a finalidade exclusiva de debater.

No decorrer do trabalho, vários projetos individuais foram ganhando contorno definido, no que diz respeito à produção artesanal. Algumas pessoas definiram estilos próprios, outros passaram a usar o mesmo material para confeccionar outros objetos. Outros, ainda, passaram a financiar seu material de produçáo de modo independente do grupo e estabeleceram rotinas e processos de trabalho específicos. Esses projetos individuais foram sempre apoiados pelos Terapeutas Ocupacionais que coordenavam o trabalho, exigindo ações profissionais desdobradas dos momentos grupais, tratando as demandas sempre das perspectivas individual e coletiva, simultaneamente. Nesse processo, alguns participantes seguiram caminhos próprios e se desligaram do grupo: partiram para iniciativas individuais que, ligadas ou não à confecção de bijuterias, envolviam formas de obter renda e alavancar projetos de vida. Outros permaneceram ligados ao grupo e ampliaram seus vínculos com a equipe profissional e a AMRMC.

Contudo, além dos projetos individuais, foi possível observar também a emergência de um sujeito coletivo, que pode surgir concomitantemente às oportunidades e vivências concretas de interação grupal e do contato com novos desafios e espaços de vida, mercados de trocas sociais e simbólicas. Desse modo, decorre que, dessas experiências grupais, a marca principal parece ter sido a constatação, por parte do conjunto de integrantes, das potências latentes do grupo e de cada um: potências de produção objetiva e subjetiva, potências para a escolha e a produção de novas relaçôes. Verificou-se que as oportunidades de produção subjetiva sob novos parâmetros relacionais, mais horizontais, dialógicos e realmente abertos às inscriçôes individuais, mobilizaram mudanças tão importantes quanto as oportunidades de gerar efeitos estéticos atraentes, de produzir valores materiais e simbólicos, socialmente relevantes. Conflitos, entraves, desinvestimentos e frustraçôes também fizeram parte do processo. E, como seria de se esperar, integraram a interminável equação que representa a busca por uma condução autônoma e com sentido da vida, para cada um de nós. Certamente, também, no fluxo do cotidiano do trabalho estiverem presentes muitos outros elementos que não conseguimos identificar e descrever aqui.

O trabalho junto a esses grupos teve um momento de transição nitidamente demarcável, o que resulta, também, no limite da descrição e reflexão a que nos propusemos. Esse trabalho ganhou contorno distinto na medida em que foi atingido pela normatização 
proposta pelo programa "Frentes de Trabalho", da Secretaria Especial de Relaçôes de Trabalho em conjunto com a Secretaria de Assistência Social do Estado de São Paulo. Esse programa ofereceu trabalho e remuneração temporária em forma de bolsa e transformou em bolsista grande parte dos integrantes dos grupos, já que estes foram indicados como beneficiários pela AMRMC, que se tornou instituição parceira no desenvolvimento do programa. Sob essas novas condições, outros desafios foram colocados e, a partir de então, outros caminhos foram desenvolvidos.

\section{Considerações finais: movimentando fronteiras}

A oferta dessas atividades grupais, desenvolvidas com base nas referências da T.O. Social no contexto daquele Núcleo de Convivência, mostrou-se uma estratégia importante no atendimento à parte das demandas apresentadas por pessoas em situação de rua. Tê-las vivenciado e ter conhecido os significados atribuídos a essas atividades grupais pelos diferentes participantes permitem refletir que estas parecem ter sido experiências catalisadoras da construção de novos territórios existenciais. Claro que não se trata de afirmar que os participantes do grupo modificaram substancialmente suas condiçôes de vida, mas ao terem encontrado oportunidades reais de (re)descobrirem-se em sua humanidade, colocaram em movimento possibilidades de se reconectar com rotas que podem alcançar desejos, projetos e produção de vida.

Uma possibilidade de representar e descrever o trabalho realizado é sob a perspectiva de sua relação com diferentes fronteiras. Pode-se iniciar afirmando a importância da permeabilidade e da flexibilidade das fronteiras do grupo, não apenas no que diz respeito à sua composição, permanentemente aberta a novos integrantes, mas principalmente no que diz respeito às possibilidades concretas de instalação de novos contornos e identidades grupais, dados a partir de atuaçôes e marcas individuais, ainda que estas sejam pouco estáveis, inconstantes, ou, às vezes, até transitórias. Muitas vezes, o que se viu foi que o processo de combate às forças que instalam o isolamento implicou, para os integrantes do grupo, num repetido movimento de adesão e desistência de projetos, proposiçóes, identidades e laços. Não havia projetos elaborados à priori. Foram construídos na liberdade de agir e de interagir, de ir e voltar atrás, de se lançar e recuar, experimentando produçóes materiais e simbólicas.
Em consonância com a ideia de produzir espaço de amplo acolhimento, os objetivos iniciais da intervenção não a aprisionaram. Num contexto previamente delineado, no qual a criação e a produçáo eram mediadoras de vínculos, foi possível operar com objetivos variados e maleáveis, definidos na relação com os participantes. A confecção de bijuterias subsidiou e favoreceu a criação de diferentes oportunidades de construção de identidade - como a de atuar para o autocuidado ou o cuidado das relaçóes afetivas constituídas ou em constituição, a de rever e valorizar histórias e saberes, a de colocar na produção material as escolhas e singularidades pessoais, a conexáo com o universo do mercado de trabalho artesanal, entre algumas outras. Para que isso acontecesse, as açóes profissionais desdobraram-se do momento da realização dos grupos para outros espaços/tempos/contextos, nos quais se seguiu, igualmente, buscando instalar oportunidades de os sujeitos romperem com condiçóes impostas por complexos processos de exclusão dos direitos sociais: o silêncio, o isolamento, a inacessibilidade, a impossibilidade de criar/produzir, o desvalor pessoal e social, o desconhecimento, as descontinuidades, a falta de projeção de futuro, o desligamento da história e dos vínculos vividos anteriormente. Afinal, são necessárias muitas estratégias para expandir as fronteiras que demarcam a circulação física e relacional da população que vive em situação de rua.

Do mesmo modo, pode-se dizer que, do ponto de vista metodológico, o rompimento com as fronteiras que decorrem de modelos fixos, pré-estabelecidos, foi imperativo. Delinearam-se fronteiras vivas, móveis, colocadas em permanente tensão, na medida em que as açóes foram sendo definidas essencialmente mediante a avaliação das necessidades relativas à constituição dos integrantes enquanto sujeitos de direito. Ainda nesse âmbito, buscou-se desconstruir as fronteiras que separam as intervençôes que enfocam a qualidade do produto daquelas que priorizam a sociabilidade. Nos grupos, ambos os polos constituíram-se como eixos de atenção e ação. $\mathrm{O}$ foco no produto permitiu a conexáo com universos pontuados pela valorização de saberes e habilidades, a partir dos quais podem ser vislumbrados processos de aquisição, de crescimento, de progressão e de superação. Além disso, a geraçáo de objetos com valor social possibilitou à parte dos integrantes do grupo uma incursão inicial menos frágil nos mercados de trocas e nas dinâmicas de negociação social, permitindo o fortalecimento de uma contratualidade real. $\mathrm{O}$ artesanato produzido com cuidado técnico e estético, e com materiais de boa qualidade, portava e disseminava o valor do próprio artesão enquanto 
parte integrante do mundo das interaçóes sociais, promovendo a validação de saberes e fazeres. Contudo, o trabalho desenvolvido nos grupos se deparou, também, com a necessidade de produzir uma cultura interna de validação coletiva. Desse modo, o foco na sociabilidade problematizou o respeito às diferenças de interesse, de ritmo de ação, de necessidade de apoio e de motivos para a permanência no grupo, entre outras diferenças. E, assim, da constatação grupal da diversidade, buscou-se que, em última instância, fosse ressaltado o caráter enriquecedor e vivificante dessa experiência.

\section{Referências}

ALVAREZ, A. M. S. A resiliência e o morar na rua: estudo com moradores de rua - crianças e adultos - na cidade de São Paulo. 1999. 198 f. Dissertação (Mestrado em Saúde Pública)-Universidade de São Paulo, São Paulo, 1999.

BARROS, D. Terapia Ocupacional Social: o caminho se faz ao caminhar. Revista de Terapia Ocupacional da Universidade de São Paulo, v. 15, n. 3, p. 90-97, 2004.

BRASIL. Ministério do Desenvolvimento Social e Combate à Fome - MDS. Sumário executivo. Pesquisa Nacional sobre a população em situação de rua. Brasília: Coordenadoria Geral de Publicaçóes Técnicas, 2008.

BRASIL. Decreto n. 7053, de 23 de dezembro de 2009. Institui a Política Nacional para a População em situação de rua e seu Comitê Intersetorial de Acompanhamento e Monitoramento, e dá outras providências. Diário Oficial da República Federativa do Brasil, Brasília, DF, 23 dez. 2009.

BURSZTYN, M. Da pobreza à miséria, da miséria à exclusão: o caso das populaçóes de rua. In: BURSZTYN, M. No meio da rua: Nômades, excluídos, viradores. Rio de Janeiro: Garamond, 2000. p. 27-55.

CASTEL, R. Da indigência à exclusão, a desfiliação: precariedade do trabalho e vulnerabilidade relacional.
In: LANCETTI, A. (Org.). Grupos e coletivos. São Paulo: Hucitec, 1994. p. 21-48 (Saúde, Loucura, n. 4).

CASTEL, R. Metamorfoses da questão social: uma crônica do salário. 5. ed. Petrópolis: Vozes, 1998.

GALVANI, D. Itinerários e estratégias na construção de redes sociais e identidades de pessoas em situação de rua na cidade de São Paulo. 2008. 261 f. Dissertação (Mestrado em Ciências)-Faculdade de Medicina, Universidade de São Paulo, São Paulo, 2008.

GALVANI, D.; BARROS, D. D. Pedro e seus circuitos na cidade de São Paulo: religiosidade e situação de rua. Interface - Comunicação, Saude, Educação, v. 14, n. 35, p. 767-79, 2010. http://dx.doi.org/10.1590/ S1414-32832010005000022

JUNCÁ, D. C. M. Mais que sobras e sobrantes: trajetórias de sujeitos no lixo. 2004. 237 f. Tese (Doutorado em Saúde Pública)-Escola Nacional de Saúde Pública, Fundação Oswaldo Cruz, 2004.

KUBOTA, A. C.; PIRES, C. B.; NEVES, L. P. O morador de rua: perspectivas conceituais. Revita Bioethikos - Centro Universitário São Camilo, v. 2, n. 2, p. 223-33, 2008.

MATTOS, R. M. Situação de rua e modernidade: a saída das ruas como processo de criação de novas formas de vida na atualidade. 2006. 157 f. Dissertação (Mestrado em Psicologia)-Universidade São Marcos, São Paulo, 2006.

NASSER, A. C. Sair para o Mundo - Trabalho, família e lazer na vida de excluidos. São Paulo: HUCITEC-FAPESP, 2001.

ROSA, C. M. M. Vidas de rua. São Paulo: Hucitec Associação Rede Rua, 2005.

TOSTA, T. L. D. Memória das ruas, memórias da exclusão. In: BURSZTYN, M. (Org.). No meio da rua: Nômades, excluídos e viradores. Rio de Janeiro: Garamond, 2000. p. 201-227.

VARANDA, W.; ADORNO, C. F. Descartáveis urbanos: discutindo a complexidade da população de rua e o desafio para políticas públicas de saúde. Saúde e Sociedade, v. 13, n. 1, p. 56-69, 2004.

\section{Autores}

\section{Marta Carvalho de Almeida}

Doutora em Saúde Coletiva, Universidade Estadual de Campinas - UNICAMP, Professora Dra. do Departamento de Fisioterapia, Fonoaudiologia e Terapia Ocupacional, Universidade de São Paulo -USP, Sao Paulo, SP, Brasil

\section{Denise Dias Barros}

Doutora em Sociologia, Universidade de São Paulo - USP, Professora Dra. do Departamento de Fisioterapia, Fonoaudiologia e Terapia Ocupacional, Universidade de São Paulo - USP, Sao Paulo, SP, Brasil

\section{Débora Galvani}

Mestre em Ciências da Reabilitação, Faculdade de Medicina, Universidade de São Paulo - USP, Terapeuta Ocupacional, Departamento de Fisioterapia, Fonoaudiologia e Terapia Ocupacional, Universidade de São Paulo - USP, São Paulo, SP, Brasil 


\section{Tiy de Albuquerque Maranháo Reis}

Mestre em Ciências da Reabilitação, Terapeuta Ocupacional - Projeto METUIA, Faculdade de Medicina, Universidade de São Paulo - USP, São Paulo, SP, Brasil

\section{Contribuição dos Autores}

Todas as autoras foram responáveis pela concepção e redação do manuscrito, assim como pela sua aprovação final para publicação.

\section{Notas}

${ }^{1}$ Grupo interinstitucional de estudos, formação e açôes pela cidadania de crianças, adolescentes e adultos em processos de ruptura das redes sociais de suporte.

2 Plano Municipal de Assistência Social, "PLAS-SP/2006", da Secretaria Municipal de Assistência e Desenvolvimento Social (SMADS), da Cidade de São Paulo.

${ }^{3}$ Entre esses se incluíam estudantes e estagiários de Terapia Ocupacional.

${ }^{4} \mathrm{O}$ trabalho contou com apoio do Fundo de Cultura e Extensão da Universidade de São Paulo, o que possibilitou a compra de materiais e instrumentos em quantidade e qualidade adequadas aos objetivos propostos. 
